\title{
Manejo integrado de plagas en viñedos, desafío sólo para amantes de la sustentabilidad
}

\author{
José Luis Miano ${ }^{1, a}$, Marion Lannoy² y Mariana Rodíguez Rolfi \\ ${ }^{1}$ José Luis Miano, Director AgroHuarpes, Los peralitos 783, CP 5505 Chacras de Coria, Luján de Cuyo - Mendoza, \\ Argentina \\ ${ }^{2}$ AgroHuarpes. Empresa de investigación aplicada y consultoría
}

\begin{abstract}
Resumen. El contexto de plagas asociadas al cultivo de la vid está en constante cambio. El manejo integrado de estos factores implica una toma de decisiones dentro de un marco de sostenibilidad económico, cultural y ambiental. El monitoreo es la herramienta que combina vigilancia y definición de los momentos oportunos de control para cualquiera de los factores que atenten contra la sanidad del cultivo de la vid y la calidad de la producción. La "cochinilla harinosa de la vid" Planococcus ficus S. es una plaga asociada al viñedo en prácticamente todas las regiones vitícolas de Argentina, afectando el normal desarrollo del cultivo por su actividad y debido a la transmisión de virus. Dos años de seguimiento de la fenología de esta plaga han permitido establecer pautas claras y oportunas de control, disminuyendo el riesgo de aparición de residuos de plaguicidas en vinos, seleccionando mejor las herramientas químicas a utilizar, rotando los plaguicidas y generando medidas específicas para cada cuartel y/o región. Se ha logrado mantener la severidad de ataque por debajo del 5\% al momento de cosecha en San Juan y disminuir la presencia en un 22\% en Cafayate, reduciendo la severidad entre un 23\% a un $70 \%$.
\end{abstract}

\section{Introducción}

\subsection{Descripción general de la plaga}

La "cochinilla harinosa de la vid" Planococcus ficus (Signoret) (Hemiptera, Pseudococcidae) es una plaga asociada a viñedos en muchas regiones vitícolas del mundo tales como Europa [1] y países productores como Estados Unidos [2], Sud África [3], Argentina [4], Chile [5], entre otros. Por tratarse de un insecto chupador, su hábito alimenticio implica la succión de savia desde el floema, con excreciones azucaradas que afectan las plantas cubriendo tronco, hojas y frutos con hongos que desarrollan sobre este sustrato [6].

Cumple en Argentina entre 5 y 6 generaciones al año, pasando el invierno principalmente como huevo bajo la corteza [7]. Se ha podido comprobar también, que puede permanecer protegida en la zona del cuello de la planta (subterráneo), especialmente en años con inviernos muy fríos o durante la ocurrencia de heladas tardías [8]. Los huevos de invierno comienzan a eclosionar lentamente a partir del aumento de temperaturas en meses cercanos a la primavera. Así, en Septiembre/Octubre se produce el primer movimiento de ninfas de la temporada. Dependiendo de las condiciones generales de temperaturas reinantes, éstas pueden avanzar hasta brazos o base de los pitones y cargadores, o bien permanecer en el tronco, bajo la corteza, para restablecer colonias lo suficientemente fuertes que permitan continuar movilizándose más tarde. $\mathrm{Si}$ bien las generaciones posteriores se desarrollarán principalmente de manera expuesta en los órganos aéreos de la planta, una porción de la población se mantendrá durante todo el período estival bajo la corteza $[1,7,8]$.

\footnotetext{
a e-mail: jlmiano@agrohuarpes.com
}

Es normal encontrar asociación simbiótica con hormigas de diversos géneros tales como Dorymyrmex, Linepithema, Pheidole, Solenopsis, Camponotus y Brachymyrmex, las que se encargan no solo de protegerlas de enemigos naturales sino además de asistirlas durante su dispersión entre plantas de un mismo viñedo [1,9]. Su asociación es tan importante que durante las primeras etapas de desarrollo de la plaga, momento en el cual la observación directa de ninfas de cochinilla se hace especialmente dificultosa, el movimiento de hormigas puede resultar una buena alerta respecto del comienzo de actividad de la plaga.

\subsection{Daños asociados}

Si bien $P$. ficus (S.) no es el único Pseudococcido citado en vid en Argentina, es la única especie que se conoce produciendo daños económicos al cultivo. Entre los aspectos más importantes cabe destacar el decaimiento general de la planta que, como consecuencia de la succión de savia, puede llevar al secado de hojas, brotes completos y hasta matar la planta afectada [10]. La eyección de "melaza", sustrato donde se reproducen hongos de diversos géneros, puede ser tan importante que el aspecto de los racimos y su capacidad de ser fermentados sin afectar la calidad de los vinos puede verse comprometida [11].

En el caso de uva de mesa y por tratarse de una plaga cuarentenaria, la sola presencia de alguna forma de la cochinilla puede implicar el rechazo del producto en muchos países destino.

Un tercer aspecto de suma importancia en cuanto a los daños relativos a la presencia de $P$. ficus $\mathrm{S}$. en viñedos, es que se trata de un vector de la "enfermedad de virus enrolladores de la hoja", pertenecientes a la familia 
Closteroviridae, famosa no solo por la rápida dispersión que ha tenido nivel mundial, sino además porque está considerada la enfermedades viral más seria asociada a este cultivo [1,12-14]. Una alta tasa de transmisión ha podido ser comprobada ya para los virus GLRaV-3 y GLRaV-5, por parte de Planococcus ficus S [14].

\subsection{Manejo Integrado de Plagas}

El Manejo Integrado de Plagas (MIP) es la combinación de prácticas y herramientas de manejo tendientes a mantener en buen estado fitosanitario los cultivos, minimizando el uso de plaguicidas [15].

Se sabe que el monitoreo de "cochinillas blandas" en vid es una práctica tediosa y que impone un gran tiempo de dedicación para llegar a resultados promisorios [16]. El comportamiento de una plaga tan dependiente de condiciones ambientales como es $P$. ficus puede resultar muy diferente si consideramos distintos sitios de cultivo $[17,18]$. La toma de decisiones en cuanto al control de esta plaga no puede, por este hecho, referirse al comportamiento general, sin tener en cuenta la velocidad de desarrollo y/o movimiento de las sucesivas generaciones hacia los órganos aéreos de la planta.

Los productos normalmente asociados al control de cochinillas en vid pertenecen a familias químicas conocidas en el mundo entero. Los neonicotinoides tales como imidacloprid y organofosforados como clorpirifos, dimetoato y metil pirimifos resultan las herramientas más utilizadas para lograr este fin [1,20,21]. Aún a pesar de que muchas de estas substancias están asociadas a fuertes impactos sobre organismos benéficos [1,22-24], los aspectos de costos de producción y en algunos casos el desconocimiento de otras alternativas, han acentuado el uso repetido de pocos plaguicidas lo que en el mediano y largo plazo implicará problemas de resistencias y riesgos de residuos en uvas y vinos.

Nuevas y más amigables técnicas de control como el uso de confusión sexual y/o productos como spirotetramat han sido probadas con excelentes resultados en diversas regiones vitícolas del mundo [25]. Estas herramientas asociadas al momento oportuno de control establecido mediante monitoreo, permiten la efectiva práctica de programas de manejo integrado en el cultivo de la vid.

El objetivo de este trabajo es conocer la fenología de la plaga Planococcus ficus Sig. en viñedos de San Juan y Cafayate, implementar estrategias de control integrado y disminuir la incidencia de esta plaga, cuidando los residuos de plaguicidas y la aparición de plagas secundarias.

\section{Materiales y métodos}

Dos diferentes zonas vitícolas de la provincia de San Juan: Media Agua y Pocito sumadas a Cafayate fueron los tres sitios donde se estableció el sistema de monitoreo de "cochinilla harinosa" y vigilancia de otras problemáticas que pudieran surgir. En los viñedos seleccionados se colocaron estaciones de monitoreo, que consisten en plantas con distintos grados de ataque de cochinilla ubicadas en diferentes puntos de diversos cuarteles. Así, en parcelas donde esta plaga ha logrado niveles muy elevados de desarrollo se estableció una densidad mayor de estaciones, en los cuarteles colindantes una densidad intermedia y una baja en aquellos donde el historial indica la presencia ocasional de $P$. ficus S., logrando establecer 10,5 y 3 puntos de observación por cuartel, respectivamente. A cada planta seleccionada se le adjudicó un código numérico que permita identificarla inequívocamente, el cual se compone por el $\mathrm{n}^{\circ}$ de cuartel, el $n^{\circ}$ de hilera, el $n^{\circ}$ de claro (o posición en el caso de parrales) y el $\mathrm{n}^{\circ}$ de planta, así el código 6.5.23.4 indica que la planta del cuadro 6 , hilera 5 , claro 23 y $4^{\mathrm{a}}$ planta de este claro es aquella sobre la que debo tomar lectura del estado de la plaga. Igualmente, para facilitar la tarea, cada estación también fue indicada con cinta peligro.

El monitoreo se lleva a cabo de modo no destructivo, es decir, cada planta es observada abriendo parte de la corteza en distintos puntos y dejándola en igual posición posterior a la toma de datos. Esto permite que el desarrollo de las colonias bajo la corteza no sea disturbado y que el movimiento que la colonia pueda sufrir a lo largo de la temporada refleje la dispersión natural de las cochinillas. Este mismo tipo de observación se realiza en brazos, base de pitones, brotes, hojas y racimos, extendiéndose por un lapso de entre 1 a 3 minutos por planta, dependiendo del grado de desarrollo que pueda encontrarse. Dicha metodología se repite tres veces por mes, anotando los estadios de la plaga que se observan asociando símbolos que indican el grado de importancia relativa que cada uno tiene, para lo cual un signo de suma $(+)$ significará "bajo", dos símbolos $(++)$ medio y tres $(+++)$ alto. En el caso de no encontrar diferencias fácilmente reconocibles se puede anotar $\mathrm{TF}=$ todas la formas en aproximadamente igual número u "ovi" si se observan ovisacos acompañando los estadios presentes.

Por otro lado se mantiene una constante vigilancia respecto del movimiento de hormigas y contra otros agentes perjudiciales como enfermedades, ácaros u otros insectos está siendo registrada y estudiada.

Las observaciones consecutivas permiten observar el grado de avance de la cochinilla en la planta, la velocidad con la que se desarrollan y el sector de la planta donde se concentran más las distintas formas, generando así "alarmas de Momento Oportuno de Control" (MOC) cuando ninfas de primero y segundo estadio llegan a sitios expuestos donde la plaga puede ser controlada. Simultáneamente se avisará de la posibilidad de combinar controles si otras plagas se hicieran presentes.

Los cuarteles donde se realizan los monitoreos son evaluados al momento de cosecha, calculando incidencia y severidad de ataque, tomando el porcentaje de plantas afectadas sobre el total para el primer parámetro y el porcentaje de racimos con presencia de cochinilla para el segundo.

\section{Resultados}

\subsection{Desarrollo de la fenología de la plaga}

Tras dos campañas de monitoreo en los viñedos de San Juan, se pudo corroborar que la fenología de la "cochinilla harinosa de la vid" difiere levemente entre zonas y notablemente entre temporadas. Así durante la campaña 2012/13, los primeros movimientos de 
ninfas en Cañada Honda fueron detectados desde fines de septiembre/2012 llegando a completarse a fines de Octubre/2012. Posteriormente, la segunda generación se desarrolló entre Noviembre y Diciembre del mismo año y entre el 5 y el 15 de Enero de 2013 se cumplió la $3^{\mathrm{a}}$ generación. Se completaron durante este año 6 generaciones en total, transcurriendo en forma muy superpuestas desde la $4^{\mathrm{a}}$ a la $6^{\mathrm{a}}$ entre los meses de Febrero a Abril de 2013. Complementariamente durante la misma temporada, en la localidad de Pocito el inicio de actividades estuvo para las dos primeras generaciones alrededor de 15 días retrasados con respecto a Cañada Honda. Luego, a partir de Enero de 2013, la velocidad de desarrollo de la plaga se hizo similar entre ambas zonas.

La temporada 2013/14 tuvo particularidades desde su inicio. Las condiciones climáticas se mantuvieron frescas hasta finales de Septiembre, ocurriendo en este momento una helada tardía que afectó no solo el normal desarrollo fenológico de la vid sino también el comportamiento biológico de la cochinilla harinosa $P$. ficus S. En esta etapa del monitoreo se pudo constatar la presencia de la mayoría de las colonias bajo tierra, protegidas a la altura del cuello de la planta. Los primeros movimientos de ninfas comenzaron a partir del 20 de Octubre de 2013, observando un rápido ascenso hacia brazos y base de los brotes. Una gran superposición de diversos estadios ninfales, adultos y adultos con ovisaco se mantuvo casi constantemente hasta cumplir con 5 generaciones completas. El solapamiento de todas las formas biológicas se debió principalmente a la lenta eclosión de los huevos de invierno y de $2^{\mathrm{a}}$ generación los que se encontraron con las ninfas de $3^{\mathrm{a}}$ y $4^{\mathrm{a}}$ generación movilizándose. Solo la tercera generación, que comenzó alrededor del 20 de Enero de 2014 pudo identificarse de forma aislada. Los posteriores inconvenientes climáticos, dado por las lluvias y bajas temperaturas medias derivaron en un retraso de la $4^{\mathrm{a}}$ generación y el corte de la biología durante la $5^{\mathrm{a}}$. En la localidad de Pocito, se mantuvieron en vigilancia diferentes cuarteles de la var. Pinot Gris, en los cuales se observó un comportamiento particular de la cochinilla, la que consistentemente tiende a subir hasta el racimo a partir de la segunda generación, sin importar la temporada de que se trate. Este hecho hizo replantear el esquema de control para la segunda temporada de trabajo.

El seguimiento por monitoreo permitió también la detección temprana de ácaros en número suficiente como para justificar una intervención de control. En algunos casos fueron observadas ciertas sintomatologías extrañas que se descartaron como problemáticas potencialmente peligrosas una vez que se analizaron.

En la localidad de Cafayate, provincia de Salta, el seguimiento se llevó a cabo desde la temporada 2013/14, observándose un panorama especialmente tardío en cuanto al comienzo de la actividad biológica de P. ficus S. Aun a pesar de esta situación la plaga normalizó rápidamente y no se produjo tanta superposición generacional como la observada en San Juan. Así los primeros días del mes de noviembre aconteció el primer movimiento de ninfas, observándose la segunda generación a principios de Diciembre y a finales del mismo mes el inicio de la tercera. En esta zona la plaga alcanzó su sexta generación sin inconvenientes.
Tabla 1. Descripción de los tratamientos realizados. San Juan. Temporada 2012/ 2013.

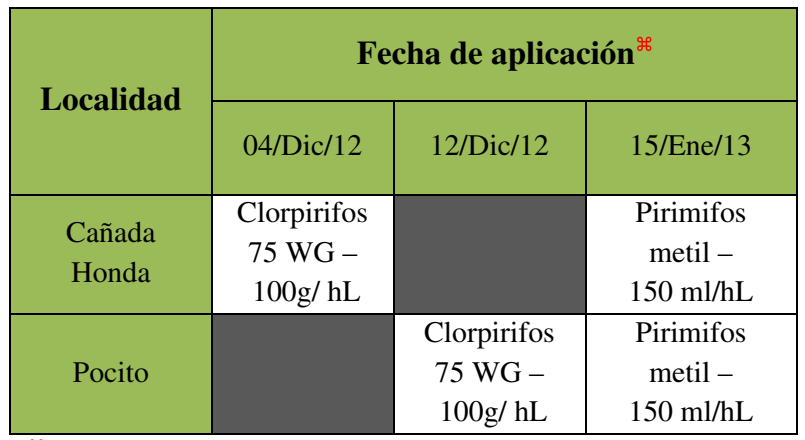

${ }^{\mathscr{H}}$ Un tratamiento antecedió a los descri ptos en esta tabla. Dimetoato $50 E$ fue aplicado a razón de $150 \mathrm{ml} / \mathrm{hL}$ temprano en la temporada por calendario regular.

\subsection{Definición de los tratamientos fitosanitarios}

La determinación del momento de las aplicaciones, así como el producto a utilizarse y especificaciones respecto de la forma de llevar a cabo la tarea se formularon en forma independiente para cada caso.

Durante la primera temporada de trabajo (2012/13) en las localidades de San Juan, pudo constatarse la débil eficacia de control obtenida de un tratamiento temprano mediante las lecturas de las estaciones de monitoreo. De este modo y con el sistema de seguimiento ya instalado se definió el momento para realizar las subsiguientes y los productos a utilizar (Tabla 1).

Durante la segunda temporada de seguimiento, las aplicaciones fueron posicionadas de acuerdo a los datos obtenidos del monitoreo. De este modo pudo trabajarse con aplicaciones más tempranas en la temporada, persiguiendo el objetivo de reducir fuertemente la gran población de ninfas de distintas generaciones antes que éstas pudieran llegar al racimo e instalarse. Dos metodologías fueron adoptadas por separado: en la localidad de Pocito se optó por dos aplicaciones complementarias de Imidacloprid vía riego por goteo y posteriormente spirotetramat foliar. En el caso de Cañada Honda se utilizaron los productos en stock ya destinados al control de cochinilla y se focalizó en utilizarlos del modo más estratégico posible (Tabla 2).

En Cafayate, provincia de Salta, se partió basados en el conocimiento de la incidencia de ataque de cochinillas en la temporada precedente al comienzo de los monitoreos. Así, sabiendo de los sectores con mayor presión de desarrollo, se instalaron parcelas comparativas de distintas estrategias de control (Tabla 3). Las intervenciones fitosanitarias están en cada caso orientadas a los controles tempranos que permitan llegar a cosecha con más de 60 días desde la última aplicación.

Los resultados obtenidos en ambas campañas en San Juan son ampliamente satisfactorios (Tabla 4). Aun si las realidades de cada temporada se diferencian notablemente, en ambos casos se pudo reducir el número de aplicaciones en una gran parte de las fincas bajo monitoreo, manteniendo las poblaciones de cochinillas bajo control. 
Tabla 2. Descripción de los tratamientos realizados. San Juan. Temporada 2013/ 2014.

\begin{tabular}{|c|c|c|c|}
\hline \multirow{2}{*}{ Localidad } & \multicolumn{3}{|c|}{ Fecha de aplicación } \\
\hline & 10/Nov/13 & 10/Dic/13 & 28/Dic/13* \\
\hline $\begin{array}{l}\text { Cañada } \\
\text { Honda }\end{array}$ & $\begin{array}{c}\text { Dimetoato } \\
50 \mathrm{E}- \\
150 \mathrm{ml} / \mathrm{hL} \\
+ \\
\text { Spirodiclofen } \\
30 \mathrm{ml} / \mathrm{hL}\end{array}$ & $\begin{array}{l}\text { Dimetoato } \\
50 \mathrm{E}- \\
150 \mathrm{ml} / \mathrm{hL}\end{array}$ & $\begin{array}{c}\text { Pirimifos } \\
\text { metil - } \\
150 \mathrm{ml} / \mathrm{hL}\end{array}$ \\
\hline Pocito & $\begin{array}{l}\text { Imidacloprid } \\
35 \mathrm{SC} \\
800 \mathrm{~g} \mathrm{ia} / \mathrm{ha}\end{array}$ & $\begin{array}{c}\text { Spirotetramat } \\
900 \mathrm{ml} / \mathrm{ha} \\
+ \\
\text { Orobor } 4 \% 0\end{array}$ & \\
\hline
\end{tabular}

* Aplicación solo en el $25 \%$ de los cuarteles. Picos orientados a la zona de producción. Gasto de 500 L/ha.

Tabla 3. Descripción de los tratamientos realizados. Cafayate, Salta. Temporada 2013/14.

\begin{tabular}{|c|c|c|c|}
\hline \multirow{2}{*}{$\begin{array}{c}\text { Identificación/ } \\
\text { cuartel }\end{array}$} & \multicolumn{3}{|c|}{ Fecha de aplicación } \\
\hline & 08/Nov/13 & 02/Dic/13 & 28/Ene/14 \\
\hline $\begin{array}{l}\text { Bonarda, } \\
\text { Cuartel } 1\end{array}$ & $\begin{array}{l}\text { Spirotetramat } \\
900 \mathrm{ml} / \mathrm{ha}+ \\
\text { Orobor } 4 \% 0\end{array}$ & $\begin{array}{l}\text { Spirotetramat } \\
900 \mathrm{ml} / \mathrm{ha}+ \\
\text { Orobor } 4 \% 0\end{array}$ & $\begin{array}{c}\text { Pirimifos } \\
\text { metil - } \\
150 \mathrm{ml} / \mathrm{hL}\end{array}$ \\
\hline $\begin{array}{l}\text { Bonarda, } \\
\text { Cuartel } 2\end{array}$ & $\begin{array}{c}\text { Dimetoato } 50 \\
\text { E - } \\
150 \mathrm{ml} / \mathrm{hL}\end{array}$ & $\begin{array}{c}\text { Dimetoato } 50 \\
\text { E - } \\
150 \mathrm{ml} / \mathrm{hL}\end{array}$ & $\begin{array}{c}\text { Pirimifos } \\
\text { metil - } \\
150 \mathrm{ml} / \mathrm{hL}\end{array}$ \\
\hline $\begin{array}{l}\text { Bonarda } \\
\text { (sector) } \\
\text { Cuarteles } \\
1 \text { y } 2\end{array}$ & $\begin{array}{l}\text { Buprofezim } \\
130 \mathrm{~g} / \mathrm{ha}\end{array}$ & $\begin{array}{l}\text { Buprofezim } \\
130 \mathrm{~g} / \mathrm{ha}\end{array}$ & $\begin{array}{c}\text { Pirimifos } \\
\text { metil - } \\
150 \mathrm{ml} / \mathrm{hL}\end{array}$ \\
\hline
\end{tabular}

Los resultados de control obtenidos en Cafayate demuestran claramente que programas con menor impacto sobre benéficos, de mejores propiedades en cuanto a inducción de plagas secundarias y manejo de la resistencia y características ambientales más amigables pueden resultar en controles tan aceptables o aún mejores que los productos normalmente asociados a los programas fitosanitarios contra cochinillas. Cabe resaltar que ante presiones de plagas tan elevadas, los reguladores de crecimiento como el Buprofezim pueden ofrecer controles que resulten poco satisfactorios (Tabla 5). A pesar de haber reducido en forma importante el desarrollo de las poblaciones, los resultados demuestran que en primera instancia se ha controlado en mayor proporción el avance de las cochinillas hacia los racimos, que la disminución del número de plantas en las cuales la cochinilla logró completar su ciclo de vida.

Las observaciones sobre cuadros colindantes a sectores con alta presión de plaga han permitido detectar zonas de dispersión de la plaga, anticipando la decisión de
Tabla 4. Resultados de intensidad de ataque a cosecha. San Juan.

\begin{tabular}{|c|c|c|c|}
\hline \multirow{2}{*}{ Localidad } & \multicolumn{3}{|c|}{ Descripción general } \\
\cline { 2 - 4 } & $\begin{array}{c}\mathrm{N}^{\circ} \text { de } \\
\text { Parcelas } \\
\text { con alto } \\
\text { nivel de } \\
\text { presión de } \\
\text { plaga }\end{array}$ & $\begin{array}{c}\text { Promedio } \\
\text { general de } \\
\text { incidencia } \\
\text { de daños a } \\
\text { cosecha }\end{array}$ & $\begin{array}{c}\mathrm{N}^{\circ} \text { de cuadros } \\
\text { que precisan } \\
\text { aplicación } \\
\text { Post-cosecha }\end{array}$ \\
\hline $\begin{array}{c}\text { Cañada } \\
\text { Honda 2013 }\end{array}$ & 7 & $\begin{array}{c}5,2 \% \text { (solo 1 } \\
\text { cuadro con } \\
14 \%)\end{array}$ & 1 \\
\hline $\begin{array}{c}\text { Cañada } \\
\text { Honda 2014 }\end{array}$ & 9 & $4,3 \%$ & $5^{* *}$ \\
\hline Pocito 2013 & 7 & $4,7 \%$ & 0 \\
\hline Pocito 2014 & 8 & $2,5 \%$ & 0 \\
\hline
\end{tabular}

**Si bien el promedio general de cada cuartel no superó el 5\% de incidencia, el $4 \%$ de las plantas irregularmente distribuidas presentaron un alto grado de desarrollo de la plaga. En estos cuarteles se decidió aplicar en post-cosecha.

Tabla 5. Resultados comparativos de incidencia y severidad de ataque a cosecha. Cafayate.

\begin{tabular}{|c|c|c|c|c|}
\hline $\begin{array}{c}\text { Tempo- } \\
\text { rada }\end{array}$ & Momento & Cuartel & $\begin{array}{c}\text { Incidencia } \\
\%\end{array}$ & $\begin{array}{c}\text { Severidad } \\
\%\end{array}$ \\
\hline 2012-13 & Marzo & Bonarda 1 & 100 & 63 \\
\cline { 2 - 5 } & Marzo & Bonarda 2 & 100 & 83 \\
\hline 2013-14 & Abril & Bonarda 1 & 67 & 22 \\
\cline { 2 - 5 } & Abril & Bonarda 2 & 78 & 27 \\
\hline 2013-14 & Abril & $\begin{array}{c}\text { Bonarda } \\
1 \text { y 2 }\end{array}$ & 100 & 79 \\
\hline
\end{tabular}

${ }^{\mathscr{H}}$ Ensayo Buprofezim 130g/ ha.

intensificar los monitoreos regulares y dando alerta de posibles intervenciones de control en la campaña siguiente.

\section{Conclusiones}

La experiencia obtenida ha permitido corroborar que el monitoreo es una pieza fundamental del Manejo Integrado de Plagas. La disminución del número de aplicaciones sobre ciertos sectores de las fincas; la determinación de la oportunidad de aplicación dentro de los programas y la necesidad de intervenciones postcosecha; la complementación entre herramientas químicas, culturales y semio-químicas en busca del mejor escenario de control; la capacitación contante de la gente a cargo de los viñedos; los controles regulares de la maquinaria utilizada que asegurarán la calidad de las aplicaciones; la experimentación in situ de otras alternativas de control; el 
uso de plaguicidas en momentos cada vez más alejados de cosecha y la consecuente disminución de riesgos de presencia de residuos en uvas y vinos; la gradual disminución de las poblaciones de cochinillas tras cada temporada de trabajo; la vigilancia y detección temprana de otros sitios de dispersión de la plaga o bien de aparición de plagas secundarias; el conocimiento fehaciente de la distribución de problemáticas asociadas a cochinillas en los viñedos propios, como las virosis, son resultados irrevocables del manejo racional del cultivo de la vid también en su aspecto fitosanitario.

A los técnicos, encargados de finca y personal en general de las empresas Graffigna y Etchart. Por su incondicional apoyo a la implementación de un programa de Manejo Integrado de Plagas en sus viñedos.

\section{Referencias bibliográficas}

[1] K. Danne, R. Sforza, Arthropod Managment in Vineyards, Springer, ch 21, pg 33. 2012

[2] K. Danne, R.P.P. Almeida, Arthropod Managment in Vineyards, Springer, ch 21, pg 25. 2012

[3] K. Danne, V.M. Walton, Arthropod Managment in Vineyards, Springer, ch 21, pg 41. 2012

[4] K. Danne, J.L. Miano, Arthropod Managment in Vineyards, Springer, ch 21, pg 30. 2012

[5] K. Danne, T. Zaveizo, Arthropod Managment in Vineyards, Springer, ch 21, pg 29. 2012

[6] K. Daane, M.L. Cooper, S.V. Triapitsyn, V.M. Walton, G.Y. Yokota, D.R. Havilan, W.J. Bentley, K. Godfrey and L.R. Wunderlych, CA, vol 62, n 4 pg 167. 2008
[7] V. C. Becerra et al, RevFCA UNCuyo, vol XXXVIII, $\mathrm{n}^{\circ} \mathbf{1}, 2006$

[8] http://www.ipm.ucdavis.edu/PMG, UC IPM, UC ANR Publication 3448. 2014

[9] M. Gonzales et al, Charlas capacitación INTA. 2005.

[10] V. M. Walton, K. L. Pringle, S Afr Enol Vitic, 25: 54-62. 2004

[11] C. Catania, et al, Informe ensayo (aún no publicado), 2007

[12] N. Duglas, K. Krüger, Eur. J. Plt. Path., 122:207-212. 2008

[13] R.P.P. Almeida, et al, APS, 98:1093-1098. 2008

[14] D.A. Golino, S.T. Sim, R. Gill and A. Rowhani, CA, vol 56, $\mathrm{n}^{\circ} 6 \mathrm{pg}$ 196. 2008

[15] http://www.fao.org/integrated-pests-management. 2014

[16] K. Danne, et al, Arthropod Managment in Vineyards, Springer, ch 21, pg 16. 2012

[17] J.H. Chong, et al, EnvEnt, 37: 323-332. 2008

[18] S. Goldasteh, et al, Codd. Archives of Biological Science, 61:329-336. 2009

[19] R.H. Gonzalez, et al, Rev Frut, 22: 17-26. 2001

[20] L. Sazo, et al, Cien Invest Agrar, 35: 177-184. 2008

[21] K.M. Daane, et al, CA, 60: 31-38. 2006

[22] V.M.Walton, et al, S Afr Enol Vitic, 22: 107-110. 2001

[23] N. Mgocheki, et al,. Afr. J. Enol. Vitic., vol. $30 n^{\circ} 2$. 2009

[24] R. Mansour, et al, Phytoparasitica J, 39: 369-376. 2011

[25] V.M. Walton, et al, J. Econ. Entomol., 99: 12801290. 2006 